\title{
A Technique for Teaching Website Effectiveness in Undergraduate I.S. Classes
}

\author{
Eugene J. Rathswohl \\ University of San Diego, San Diego, CA, USA
}

gener@sandiego.edu

\section{Abstract}

Website design practitioners and researchers have proposed criteria for effective website design based on experience and common sense, intuition, rules-of-thumb, and empirical studies of website usability. Typically, published checklists for evaluating websites emphasize design features such as information layout, navigability, and the technical performance of the website. University undergraduate students often first learn seriously about website design in introductory information systems courses. This paper describes a teaching pedagogy to help students learn how to evaluate commercial and organizational websites. The pedagogy emphasizes students developing their own criteria of website effectiveness and information quality, designing their own checklist incorporating those criteria, and then utilizing their checklist to rate websites in several e-commerce domains. The pedagogy emphasizes a mix of theoretical, practical, exercising, and real-world learning approaches.

Keywords: Website evaluation, Website quality, Website usability, undergraduate teaching

\section{Introduction}

The perspective of an information provider on the quality of a Website and the information it provides may be different from that of the information consumer. However, ultimately it is the information consumers who judge whether or not the information is fit for their uses (Khalil, 1999). Website designers need to continually improve their understanding of their information consumers' information quality needs (Conger \& Mason, 1998). Several conceptual frameworks conceptualizing the underlying aspects of information quality that are important to information consumers have been developed (Strong, Lee, \& Wang, 1997; Huang, Lee, \& Wang, 1999). These frameworks consist of several information quality categories including intrinsic, contextual, representational and accessibility information quality. Other quality dimensions include time, content, and form.

Intrinsic information quality denotes that information has quality in its own right. A literature review in this area suggests that intrinsic information quality relates primarily to the accuracy, conciseness, and scope of the information (e.g., Wang \& Strong, 1996). Contextual information quality highlights the requirement that information quality must be considered within the context of the task at hand. In order to add value to the tasks or purposes for which the information is provided, the information must relevant

Material published as part of these proceedings, either on-line or in print, is copyrighted by Informing Science. Permission to make digital or paper copy of part or all of these works for personal or classroom use is granted without fee provided that the copies are not made or distributed for profit or commercial advantage AND that copies 1) bear this notice in full and 2) give the full citation on the first page. It is permissible to abstract these works so long as credit is given. To copy in all other cases or to republish or to post on a server or to redistribute to lists requires specific permission from the publisher at Publister@intommingscience.org and complete. Additionally, this relevant information must be provided in time and in an appropriate amount. Information that comes late has no added value at all. Too large a volume of information may make it difficult for consumers to access, interpret, and understand the meaning within a reasonable time; therefore, it may have little or no added value (Strong, Lee, \& Wang, 1997). Representational in- 
formation quality includes aspects related to the format of the information (concise and consistent representation) and its meaning (interpretability and ease of understanding). This category of quality requires that Websites need to present their information in a way that is interpretable, easy to understand, and concisely and consistently represented (Thuring, 1995; Wand, 1996). Accessibility information quality emphasizes that the information system must be accessible but secure. Problems of accessibility information quality are characterized by the underlying concerns about technical accessibility of the Website. Information consumers cannot access the needed information because they may lack computing resources or because of the privacy and confidentiality of the information. Similar to the problems of inaccurate information, the accessibility problems of a Website affect reputation and value of the site and of the information provided.

The usability of a Website is a function of many independent variables, including information quality (Hlynka, 1996). There is however a lack of real insight into the relationships between a Website's information quality and perceived usability by consumers (Zhang, 1999). Such insights could help Website designers make rational design choices (Hong, 1997; Nielsen, 2002).

\section{Pedagogy for Teaching Website Effectiveness}

In this day and age of a digital information culture, there is much talk about the necessary information literacy skills students need for a productive career and life. Several taxonomies have been discussed recently, most if not all of them emphasizing conceptual, analytic, and hands-on information skills (Vitolo, 2002). Just how to design and deliver course content regarding information skills is a real challenge, in part because of the continuous rapid changes in information technology and in information industry job descriptions, and also in part because of changing student expectations regarding their university education and faculty opinions about the placement of IT courses in the curriculum (Carter, 2002).

Given the learning diversity of today's university students, a wise approach for course delivery is to emphasize a mix of learning approaches such as theoretical (e.g. lecturing and class discussion), practical (e.g. lab., student presentation, case project), problem-solving exercising in the classroom, and real-life problem-solving outside the classroom with another organization (Burkett, 2001). The overall emphasis should be on students' active participation in constructing their knowledge and skills. In the context of learning about Websites, it is not sufficient to just read the literature about website design and effectiveness; in addition, students must actively form their own informed attitudes about website quality (Khalil, 1999).

\section{Course Design}

The BUS86 information systems course is a required, lower division course for the Bachelor of Business Administration degree. The course is divided into five modules, each approximately three weeks duration. Each module focuses on a particular theme and information literacy skill set. Module 1 includes coverage of Windows, e-mail, software basics, and Internet browsers; Module 2 is hardware basics, word processing software, desktop publishing, and presentation software; Module 3 looks at decision support software and business graphics; Module 4 discusses database applications; and Module 5 covers networks and ecommerce topics and Web presentation design. Each module has at least one written assignment and several hands-on software assignments. Short essay and hands-on exams are scheduled during the semester as well.

\section{Website Effectiveness Assignment}

The Website effectiveness assignment is given to the students during the latter third of the course. The pedagogy emphasizes students developing their own criteria of Website effectiveness and information 
quality, designing their own checklist incorporating those criteria, utilizing their checklist to rate websites in several e-commerce domains, and then reporting their findings in a report.

\section{Step 1: Identify Website effectiveness criteria}

The students are directed to identify and develop their own set of criteria of website effectiveness and information quality. The teaching approach in Step 1 is theoretical - students initially learn about possible criteria via class lectures and discussions, selected readings provided on the course's Website, and reflecting on their own experiences using Websites. Students are encouraged also to access Websites that discuss Website effectiveness (e.g. Katerattanakul, 1999; Lynch, 1999). The emphasis here is to have the students sift through the myriad of possible criteria of evaluating Websites and to identify a relatively small set $(7 \pm 2)$ of highly relevant criteria with an explicit rationale of why each particular criteria is included in their list. A key idea here is that the students develop their criteria list from their own perspectives. Not surprising, the criteria typically relate to a Website's design and layout, content, and navigation features. A sample set of student-identified criteria is shown in Table 1.

\section{Step 2: Design the Checklist}

The students are directed to design a checklist template that could be used as a survey tool to rate a Website on the various criteria identified in Step 1. The teaching approach in this step is practical -- most students understand the basics of word processing and spreadsheet software; students have an opportunity here to utilize more advanced features in their checklist design, such as the use of tables, hyperlinks, etc.

\section{Step 3: Use the Checklist}

The students are then directed to utilize their checklists to rate Websites in an e-commerce domain. The teaching approach in this step is both practical and problem solving. The students use a search engine(s) of their choice to find several $(7 \pm 2)$ commercial or organizational Websites within the same industry, such as consumer electronics, clothing retail, etc. They use their checklists to evaluate and rank order the Websites. Table 2 illustrates a sample student-designed checklist layout and evaluation of several computer store Websites.

\section{Step 4: Report Results}

At the conclusion, the students write a short management report describing their activities, including a description of their checklists and the rationale for each checklist item, a description of the type of Websites they chose to evaluate, a short discussion of the rank ordering of the Websites, and conclusions and recommendations for improving the Websites. The teaching approach in this step is both practical and problem solving emphasizing the importance of packaging their work in a professional manner. 


\section{Impression on first entry (1st Impression)}

The URL/Domain Name is appropriate and meaningful

The surfer sees something meaningful within 8 seconds

The Site Name and Product/Purpose come up instantly

Text is visible (and held steady) while graphics are loaded

The Homepage looks good, and has a clean, uncluttered look

Not distracted by excessive animation or flash

\section{The Homepage contains the key facts (Homepage Content)}

Name of Organization

Shows business, products, where based

Style appropriate for target audience

Shows the sort of information available in the site

Shows name, address, telephone, fax, Email

TITLE is meaningful

\section{Page Layout}

Good use of white space

Graphics don't subtract from readability

Elements are arranged to fit within browser window

Graphics contribute to the purpose of the page

\section{All the pages obey the same rules (Page standards)}

Each web-page has a proper title

The title shows why users should look at this page

Titles are consistent with the words used to links to it

Text is shown in centered tables

\section{Shopping Experience}

Friendly and quick route to buy

Secure handling of credit card information

Order acknowledged with delivery date stated

Order tracking provided

Returns policy stated

Appropriate use of cookies

\section{Back Office Support}

Email response address on every page

What to do about faults, comments, suggestions, feedback

Same day acknowledgement of all Emails

Timely and full answer to Emails

\section{The Website achieves its purpose (Purpose Achieved)}

It is clear what the purpose of this website is

The apparent purpose has been achieved

There are appropriate images and color

It has a professional, planned, workmanlike, friendly image

There is appropriate user interaction for Key Action Points

The reply forms were easy to use and relevant to the need

I am tempted to return in the future

\section{Useful External Links are provided (External Links)}

Links are provided to relevant sources of information

Links to associated organizations are provided

Information readily available elsewhere is not repeated

There is a description of who the link is to, and why

External links are shown with the full URL

\section{The whole site has a structure (Structure)}

It is clear what the structure of the site is

Useful content is not more than three clicks from the homepag

There is a List of Contents or a Site-Map with links to every pa

Each web-page has links back to the Contents or Site-Map

There are appropriate links on to other useful pages

Search tool is provided if appropriate

\section{All Web-Pages have a reference (Reference)}

Author and name of organization on each web-page

Accreditation or acknowledgement of the source of data show

Web-Page URL shown for reference if the page is printed

Date created or last updated on each web-page

Pages that may be printed have company and contact informa

\section{Table 1: Sample set of Website evaluation criteria and rationale}


Rathswohl

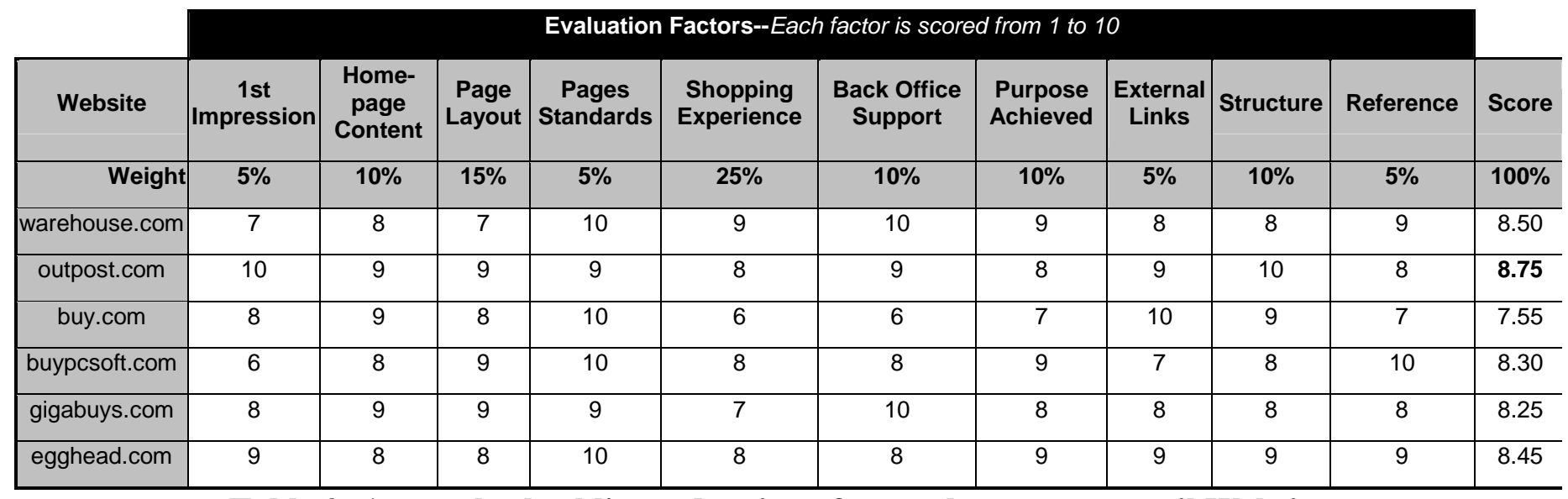

Table 2: A sample checklist and rating of several computer retail Websites

\section{Conclusion}

The Website evaluation assignment described in this paper shows a way of engaging students actively in the construction of knowledge that is meaningful and useful to them, from their perspective. The assignment allows the students to integrate a variety of conceptual and hands-on skills (e.g. Web research, word processing and/or spreadsheet document design) that results in new personal knowledge (in this case, Website effectiveness) derived from reality-based information (the review of actual Websites). This approach has been used for several semesters and elicits positive comments from the students. Having done this assignment in the introductory information systems course, students are better equipped to critically utilize Websites as information resources in their other courses and also in courses requiring them to design Web pages.

\section{References}

Alexander, J. \& Tate, M. A. (2000). Evaluating Web Resources, Widener University. http://www2.widener.edu/wolfgram-Memorial-Library/webevaluation/webeval.htm

Burkett, W.H., Compton, D.M., \& Burkett, G. G. (2001). An Examination of Computer Attitudes, Anxieties, and Aversions Among Diverse College Populations: Issues Central to Understanding Information Sciences in the New Millennium. Informing Science, 4:3, 77-85.

Carter, J. \& Boyle, R. (2002). Teaching Delivery Issues - Lessons from Computer Science. Journal of Information Technology Education, 1:2, pp. 77-89.

Conger, S. A., and Mason, R. O. (1998). Planning and Designing Effective Web Sites, Cambridge, MA: Course Technology.

Hlynka, D., \& Welsh, J. (1996). What Makes an Effective Home Page? A Critical Analysis.

http://www.umanitoba.ca/faculties/education/cmns/aect.htmn

Hong, S., \& Moriai, M. (1997). Evaluation Criteria for the Design of Commercial Web Sites. http:/hsb.baylor.edu/ramsower/ais.ac.97/papers/hong.htm

Huang, K.; Lee, Y. W.; \& Wang, R. Y. (1999). Quality Information and Knowledge, Upper Saddle River, NJ: Prentice Hall.

Katerattanakul, P. \& Siau, K. (1999). Measuring Information Quality of Web Sites: Development of an Instrument. Proceedings of the Twentieth International Conference on Information Systems, Charlotte, North Carolina, 279-286.

Khalil, O. E. M., Strong, D. M., Kahn, B. K., \& Pipino, L. L. (1999). Teaching Information Quality in Information Systems Undergraduate Education. Informing Science, 2:3, 53-59.

Lynch, P. J. \& Horton, S. (1999) Web Style Guide. Yale University Press.

http://WwW.into.med.yale.edu/caim/manual/contents.htm/ 
Technique for Teaching Website Effectiveness

Moore, G. C., \& Benbasat, I. (1991). Development of an Instrument to Measure the Perceptions of Adopting an Information Technology Innovation. Information Systems Research (2:3), 192-222.

Nathan, S. (1998). Personal Websites tttp://www.nathan.com/thoughts/personalsites/

Nielsen, J (2002) Jacob Nielsen's Useit.com Website. nttp://WwW.useit.com

Strong, D. M.; Lee, Y. W.; \& Wang, R. Y. (1997). Data Quality in Context. Communications of the ACM (40:5), 103-110.

Strong, D. M.; Lee, Y. W.; \& Wang, R. Y. (1997). 10 Potholes in the Road to Information Quality. Computer (30:8), 38-46.

Thuring, M., Hannemann, J., \& Haake, J. M. (1995). Hypermedia and Cognition: Designing for Comprehension. Communications of the ACM, (38:8), 57-74.

Vitolo, T.M. \& Coulston, C. (2002). Taxonomy of Information Literacy Competencies. Journal of Information Technology Education, 1:1, 43-51.

Wand, Y., \& Wang R. Y. (1996). Anchoring Data Quality Dimensions in Ontological Foundations. Communications of the ACM, 39:11, 86-95

Wang, R. Y., \& Strong, D. M. (1996). Beyond Accuracy: What Data Quality Means to Data Consumers. Journal of Management Information Systems, 12:4, 5-34.

Zhang, P.; von Dran, G.M.; Small, R.V.; \& Barcellos, S. (1999). Websites that Satisfy Users: A Theoretical Framework for Web User Interface Design and Evaluation. Proceedings of the American Society for Information Science, New York.

\section{Biography}

Gene Rathswohl is a faculty member of the University of San Diego where he teaches information systems courses. Prof. Rathswohl has developed recently Website design courses for undergraduate and graduate e-commerce graduate programs. He has authored articles on end-user computing and several textbooks. 